\title{
New data show life is longer, better, but more expensive
}

A new ranking system devised by scientists at the World Health Organization (WHO), which evaluates longevity in terms of healthy years versus years hampered by illness and disability, reveals that babies born in 1999 in Japan have the longest healthy life expectancy of any country, with 74.5 years. Unfortunately, independent research indicates that official forecasts have underestimated the burden of cost of an aging society, particularly in Japan.

In the WHO assessment of 191 countries, scores are based on the Disability Adjusted Life Expectancy (DALE) indicator, which subtracts the years of ill health-weighted according to severity-from the overall life expectancy to give the equivalent years of healthy life. This is a change from previous estimates, which were based on mortality data only.

Not surprisingly, the DALE system shows that healthy years are curtailed by injury, blindness, paralysis and the debilitating effects of several tropical diseases such as malaria, to a greater degree in poor than in developed countries: People in the worst-off countries lose around $14 \%$ of their lives to disability, versus $9 \%$ in the most prosperous regions. Sierra Leone is at the bottom of the table, with 25.9 years of heal thy life for babies born in 1999.
However, there are exceptions to the rule. For example, Americans spend relatively more of their life ill or disabled and die earlier than people from simiIarly advanced countries-the US ranks only 24 th, with an average of 70.0 years of healthy life. This paradox is generated by the large presence of poor communities such as Native Americans and inner-city groups, which have extremely poor health; and by death and disability due to HIV and to chronic lung disease caused by tobacco. By comparison, China has a high healthy life expectancy (62.3 years, average), given that it has $20 \%$ of the world's population.

According to Alan Lopez, coordinator of Epidemiology and Burden of Disease at the WHO and a lead author of the report, other surprises include the segregation of geographical neighbors Australia and New Zealand, with respective rankings of 2 nd and 31st. Lopez says that the disparity is difficult to explain, "but Australia has probably had more aggressive public health campaigns to prevent HIV, tobacco use and drunk driving, and to promote exercise and a better diet. A similar contrast is seen with Sweden (4th) and Denmark (28th), due largely, says Lopez, to much higher tobacco use in Denmark, especially among females.

Because of the devastating effects of
HIV-AIDS, sub-Saharan Africa accounts for the bottom 10 countries, where the disease has decimated life expectancyreducing it from 51.1 years to 46.3 years for female babies and from 47.3 years to 44.8 years for males.

Meanwhile, the recent $70 \%$ rise in premature death for Russian males means that this country has one of the widest sex gaps in the world. Healthy life expectancy is 66.4 for female babies but only 56.1 years for males. The Health Life Expectancy Rankings are available at http://www-nt.who.int/whosis/statistics/dale/dale.cfm?path =statistics, dale\&la nguage=english

Japanese people born in 1999 will doubtless be pleased to know that they could enjoy one of the longest healthiest lives on the planet, but new research shows that economic forecasts have severely underestimated the cost of decreased mortality within a population. A team of scientists from California, led by Shripad Tuljapurkar, estimates that life expectancy by 2050 in the G7 countries is going to increase beyond official estimates such that the cost of aging will be higher than present calculations-by $38.5 \%$ in Japan, $16.7 \%$ in the US, $15.9 \%$ in France, $15 \%$ in Canada, $9.3 \%$ in Italy, $8.3 \%$ in Germany and $6.9 \%$ in the UK (Nature, 405, 789; 2000).

\section{Karen Birmingham, London}

\section{US gene therapists rally at annual meeting}

Attendees at last months' American Society of Gene Therapy (ASGT) meeting in Denver hailed the conference as the most exciting in years, and claimed that it reinvigorated a field eager to move on from its worst controversy-the first death caused by gene therapy.

Spirits were lifted by good news for a variety of diseases, such as positive patient responses to gene therapy for severe combined immunodeficiency, hemophilia B, adenosine deaminase deficiency and several cancers. Researchers also reported headway in vector design. "The meeting wasn't like last year's, where one talk was exciting and all the others were 'We're trying,'" says leading gene therapist French Anderson. "Last year, we were all thrilled because there was one example of success. This time, 8 or 10 clinical trials in different areas are looking very encouraging."

Anderson believes that the 1995 Orkin-Motulsky report was the influence behind the good news. This report recommended a back-to-research approach to correct a stampede into clinical trials that failed to cure a single patient. Anderson says this year's meeting is the first to show the clinical results that have come about by improved vectors, a strategy suggested in the report.

Regulatory affairs sessions at the meeting served to remind everyone that the Gelsinger case has changed how clinical trials will be done. Food and Drug Administration (FDA) officials instructed investigators on new rules requiring that clinical trial monitoring procedures be approved by FDA before trials can begin, and officials of the National Institute of Health's
Recombinant DNA Affairs Committee reminded them of their responsibility to expeditiously report serious adverse trial events. Oversight will be reinforced by the Office of Human Research Protection-the new name for the restructured Office for Protection from Research Risks. The new office will also have a new director this September in E. Greg Koski, a Harvard Medical School professor with extensive experience in human subjects protection programs in teaching hospitals.

New rules and positive clinical results may ease the concerns about safety that have made trial enrollments more difficult. "The recent events have slowed patient accrual for many investigators," says Katherine High of the Children's Hospital of Philadelphia, who spoke at the meeting about the successful gene delivery for hemophilia B.

Tom Hollon, Bethesda 